\title{
Surface Models in Heterogeneous Catalysis The Synthesis of Ammonia and the Conversion of Carbon Monoxide
}

\author{
G. PARRAVANO \\ From the Department of Chemical and Metallurgical Engineering, University of Michigan \\ Ann Arbor, Michigan
}

Received November 16, 1966, revised January 16, 1967

\begin{abstract}
The establishment of chemical equilibria between gas and solid catalysts during the synthesis of $\mathrm{NH}_{3}$ and the conversion of $\mathrm{CO}$ is considered. Suitable solid-gas equilibrium reactions are discussed. With the correct choice of the rate-controlling step, the equilibrium surface models are able to reproduce the experimental expressions for the rates of reaction. These models represent a drastic departure from the concept of a fixed, heterogeneous surface that has been extensively used in the past for the interpretation of the experimental results on the above reactions. The two approaches, however, complement each other and the validity of each one may well be justified under different experimental conditions. Thus, a model may be considered the extension of the other by modification of some of the parameters of the system.
\end{abstract}

Over the past several years many investigations have been carried out on the catalytic synthesis of $\mathrm{NH}_{3}$ and on the conversion of $\mathrm{CO}$. The studies have generally been directed toward the understanding of the nature, properties, and operation of the catalytic surface through the analysis of experimental results of reaction rates.

While the nature of the preponderant surface intermediates is still uncertain, the physical model of the surface is similar for all the reaction schemes advanced so far. Essentially, the surface is considered as a fixed array of atomic centers with catalyti: propertics controlled by the physicochemical manipulation of the catalyst prior to use. These reaction schemes assume that at synthesis conditions no modification of surface properties occurs.

At the temperatures in which both reactions have been studied, there is likelihood of ready surface mobility bringing redistribution of matter between various parts of the surface and between the surface and the gas phase. The model of a "frozen" surface, although mathematically successful, is probably unrealistic from a physical point of view and it is certainly invalid for relatively long periods of catalyst operation. It is, therefore, of interest to consider other possibilities more physically justifiable.

In this direction it seems particularly important to consider the possibility that equilibration reactions between surface and gas phase modify the chemical composition of the surface and, as a result, its chemical reactivity and catalytic activity (1). The model of an equilibrium surface must also be based upon several assumptions and, in some instances, may not turn out to be more compelling than its "frozen" counterpart, but it offors a more plausible surfacc picture, in accord with the increased knowledge of surface transport processes and consistent with the realization of the ready occurrence of the latter even at moderately low temperatures (2).

The basic ideas on the role of surface equilibration reactions in catalytic kinetics were formulated several years ago (3), but no attempt has been made to apply these concepts to the reactions of $\mathrm{NH}_{3}$ synthesis and of $\mathrm{CO}$ conversion. For the latter reaction, a recent study (4) employing a kinetic 
relaxation method has shown the correctness of treating the overall reaction as a sequence of two steps, one of which represents the equilibrium between surface and gas phase.

In this paper we wish to show that, by employing a surface model in which equilibration reactions with the gas phase take place concurrently with the catalytic reaction, and thereby modify the properties of the surface, it is possible to obtain a satisfactory agreement with the experimental rate results.

\section{Ammonia Synthesis}

A large number of studies on the reaction

$$
\mathrm{N}_{2}+3 \mathrm{H}_{2} \rightarrow 2 \mathrm{NH}_{3}
$$

have shown that the experimental observations can be satisfactorily represented by a rate expression

$$
d p_{\mathrm{NH}_{3}} / d t=k p_{\mathrm{N}_{2}}\left(p_{\mathrm{H}_{2}}^{3} / p_{\mathrm{NH}_{2}}^{2}\right)^{1-\beta}
$$

where $\beta=0.5$ for a typical iron catalyst under conditions sufficiently removed from equilibrium (5). The generally accepted interpretation of Eq. (2) considers the overall reaction occurring as a sequence of elementary steps taking place on a nonuniform catalytic surface. The surface is pictured as an array of sites with reactivity varying according to an ad hoc distribution function, which controls the chemisorption of $\mathrm{N}_{2}$. The result is a Freundlich isotherm, whose pressure dependence is assumed to be the correct value to fit the experimentally determined dependence of the rate upon the partial pressure of $\mathrm{N}_{2}$. This scheme results in a large degree of consistency among various experimental measurements of reaction rates, adsorption heats, and isotope effects. However, it is not possible to provide an independent physical justification for the assumed distribution function of the Freundlich isotherm.

In the present discussion, we shall retain two of the features common to the majority of the analytical treatments suggested so far, namely that the kinetically determining step is the chemisorption of $\mathrm{N}_{2}$ and that the preponderant surface intermediates are imine radicals, $\mathrm{NH}$, or closely analogous species containing nitrogen and hydrogen (6). This brings us to consider the following reaction sequence:

$$
\begin{gathered}
\mathrm{N}_{2}(\mathrm{~g})+\mathrm{H}_{2}(\mathrm{~g}) \rightarrow \mathrm{N}_{2} \mathrm{H}_{2}(\mathrm{a}) \\
\mathrm{N}_{2} \mathrm{H}_{2}(\mathrm{a})+2 \mathrm{H}_{2}(\mathrm{~g}) \rightarrow 2 \mathrm{NH}_{3}(\mathrm{~g})
\end{gathered}
$$

To bring out explicitly the possible influences of reaction steps (a) and (b) upon the activity of the surface, the rates of steps (a) and $(\mathbf{b}), v_{\mathrm{a}}$ and $v_{\mathrm{b}}$, are expressed in terms of first order dependence upon the gas partial pressures. Surface effects upon the rate of reaction are considered by means of a function of the concentration of surface intermediates, $f\left(\left[\mathrm{~N}_{2} \mathrm{H}_{2}\right]\right)$, or

$$
\begin{gathered}
v_{\mathrm{a}} / A=k_{\mathrm{a}} f_{\mathrm{a}}\left(\left[\mathrm{N}_{2} \mathrm{H}_{2}\right]\right) p_{\mathrm{H}_{2}} p_{\mathrm{N}_{2}}-k_{\mathrm{a}}^{\prime} f_{\mathrm{a}}^{\prime}\left(\left[\mathrm{N}_{2} \mathrm{H}_{2}\right]\right) \\
v_{\mathrm{b}} / A=k_{\mathrm{b}} f_{\mathrm{b}}\left(\left[\mathrm{N}_{2} \mathrm{H}_{2}\right]\right) p_{\mathrm{H}_{2}}^{2}-k_{\mathrm{b}}^{\prime} f^{\prime}{ }_{\mathrm{b}}\left(\left[\mathrm{N}_{2} \mathrm{H}_{2}\right]\right) \\
\times p_{\mathrm{NH}_{3}}^{2}
\end{gathered}
$$

where $k_{\mathrm{a}}, k_{\mathrm{a}}^{\prime}, k_{\mathrm{b}}, k_{\mathrm{b}}^{\prime}$ are the rate of reaction steps (a) and (b) per unit surface area, $A$, gas partial pressure, and $\left[\mathrm{N}_{2} \mathrm{H}_{2}\right]$. For step (a) at complete equilibration let us set

$$
\left[\mathrm{N}_{2} \mathrm{H}_{2}\right]_{\text {equil (a) }}=K_{\mathrm{a}} p_{\mathrm{H}_{2}} P_{\mathrm{N}}
$$

where $K_{\mathrm{a}}$ is the equilibrium constant for reaction step (a). Substituting the equilibrium condition (5) into the rate equation (3) and using the expression of the rate at equilibrium $v_{\mathrm{a}}=0$, Eq. (3) becomes

$$
\begin{aligned}
v_{\mathrm{a}} / A=k_{\mathrm{a}} f_{\mathrm{a}}\left(\left[\mathrm{N}_{2} \mathrm{H}_{2}\right]\right) & \left\{p_{\mathrm{N}_{3}} p_{\mathrm{H}_{2}}\right. \\
& \left.-\left[\mathrm{N}_{2} \mathrm{H}_{2}\right]_{\text {equil (a) }} / K_{\mathrm{a}}\right\}
\end{aligned}
$$

Similarly for reaction step (b), the equilibrium condition gives

$$
\left[\mathrm{N}_{2} \mathrm{H}_{2}\right]_{\text {equil (b) }}=\left(1 / K_{\mathrm{b}}\right)\left(p_{\mathrm{NH}_{3}} / p_{\mathrm{H}}\right)^{2}
$$

where $K_{\mathrm{b}}$ is the equilibrium constant of reaction step (b). Substituting the equilibrium condition (7) into the rate expression (4) and using the expression for the rate at equilibrium $v_{\mathrm{b}}=0$, it is found

$$
\begin{aligned}
v_{\mathrm{b}} / A=k_{\mathrm{b}} \mathrm{f}_{\mathrm{b}}\left(\left[\mathrm{N}_{2} \mathrm{H}_{2}\right]\right)\left\{p_{\mathrm{H}_{2}}^{2}\right. & \left.-\left(p_{\mathrm{NH} 3}^{2} / K_{\mathrm{b}}\left[\mathrm{N}_{2} \mathrm{H}_{2}\right]_{\text {equil (b) })}\right)\right\}
\end{aligned}
$$

In a catalytic flow reactor steady state conditions prevail, and, as a result, the concentration of adsorbed species at steady state $\left[\mathrm{N}_{2} \mathrm{H}_{2}\right]_{\text {ss }}$ must lie between $\left[\mathrm{N}_{2} \mathrm{H}_{2}\right]_{\text {equil(a) }}$ 
and $\left[\mathrm{N}_{2} \mathrm{H}_{2}\right]_{\text {equil(b). Since the majority of the }}$ experimental results indicate that $k_{\mathrm{a}}<k_{\mathrm{b}}$, we shall assume the limiting case

$$
\left[\mathrm{N}_{2} \mathrm{H}_{2}\right]_{\mathrm{ss}} \cong\left[\mathrm{N}_{2} \mathrm{H}_{2}\right]_{\text {equil (b) }}
$$

The steady state rate of reaction (1) is $v_{\mathrm{ss}} \cong v_{\mathrm{a}}$. In the rate equation (6) an explicit form of the function $f\left(\left[\mathrm{~N}_{2} \mathrm{H}_{2}\right]\right)$ should be introduced. Since the rate of formation of $\mathrm{N}_{2} \mathrm{H}_{2}$ [reaction step (a)] is adversely influenced by $\left[\mathrm{N}_{2} \mathrm{H}_{2}\right]$, it is possible to set

$$
f_{\mathrm{a}}\left(\left[\mathrm{N}_{2} \mathrm{H}_{2}\right]\right)=\left[\mathrm{N}_{2} \mathrm{H}_{2}\right]^{-m_{a}}
$$

where $m_{\mathrm{a}}$ is a constant. If reaction step (a) is the slowest of the sequence, its reverse reaction may be neglected, and from Eq. (6), $(7),(9)$, and $(10)$, one gets

$$
\begin{aligned}
v_{\mathrm{ss}} / A=v_{\mathrm{a}} / A & =k_{\mathrm{a}}\left(\left[\mathrm{N}_{2} \mathrm{H}_{2}\right]_{\mathrm{equi}}^{-m_{\mathrm{a}}(\mathrm{b})}\right) p_{\mathrm{N}_{2}} p_{\mathrm{H}_{2}} \\
& =k_{\mathrm{a}} K_{\mathrm{b}} m_{\mathrm{x}} p_{\mathrm{N}_{2}}\left(p_{\mathrm{H}_{2}}^{3} / p_{\mathrm{NH}_{3}}^{2}\right)^{m_{\mathrm{a}}}
\end{aligned}
$$

For $m_{\mathrm{a}}=0.5$, the rate expressions (11) and (2) are similar.

To carry further the analysis of the reactive surface, let us focus the discussion upon step (a) and suggest some possibilities for its occurrence. Equation (11) is rewritten as follows:

$v_{\mathrm{a}} / A=k_{\mathrm{a}}\left[\mathrm{N}_{2} \mathrm{H}_{2}\right]_{\text {equil(b) }}^{-0.5} p_{\mathrm{N}_{2}} p_{\mathrm{H}_{2}}=k_{\text {expt } 1} p_{\mathrm{N}_{\mathrm{s}}} p_{\mathrm{H} 2}$

where $k_{\text {expt } 1}=k_{\mathrm{a}} K_{\mathrm{b} 0.5}\left(p_{\mathrm{NH}_{3}} / p_{\mathrm{N}_{2}}\right)^{-1}$ is the rate coefficient obtained directly from the experimental results and $k_{\mathrm{a}}$ is the true rate constant, independent of the partial pressure of the gaseous components.

The molecular structure of the dimer radical is unknown, but likely it involves $\sigma$ and $\pi$ bonds, by $s p$ hybridization of the corresponding atomic orbitals of $\mathrm{N}_{2}$, giving a flat, linear species. The $-\mathrm{N}=\mathrm{N}-$ bond distance is $\approx 1.20 \mathrm{~A}^{\circ}\left[1.24 \mathrm{~A}^{\circ}\right.$ in $\mathrm{N}_{2}\left(\mathrm{CH}_{3}\right)_{2}$, $1.13 \mathrm{~A}^{\circ}$ in diazomethane]. In the adsorption state the dimer radical may undergo rupture of the $\pi$ bond and formation of two bonds with surface iron atoms (I). Although the influence of the $\mathrm{N}-\mathrm{Fe}$ bond upon the distance of the $-\mathrm{N}=\mathrm{N}-$ bond cannot be predicted easily, it is likely that this type of adsorption carries considerable strain in the dimeric species.

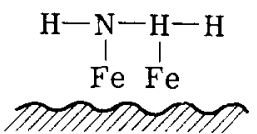

(I)

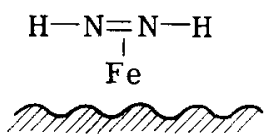

(II)
Alternatively, direct $\pi$-bond complexing with surface $\mathrm{Fe}$ atoms may be considered (II). There is increasing evidence for the role of this type of surface bond in several heterogeneous catalytic reactions (hydrogenation, isomerization, polymerization) (7), but it is less likely for bonding $\mathrm{N}_{2}$, since the corresponding $\pi$ orbitals are energetically more stable. The atomic structure of the catalytic surface is unknown, but in the presence of impurities of various kinds (catalyst, gas phase) at the temperatures employed for the synthesis, it is likely that a relatively thick surface layer compound (or alloy) may be formed with structure and properties closer to those of a metallic salt (nitride, hydride, nitrohydride) than to those of metallic Fe. Strong support for this view was obtained by measuring the adsorption of $\mathrm{N}_{2}$ during the decomposition of $\mathrm{NH}_{3}$. On W it was found that the amount adsorbed was several times as much as that required to completely saturate the surface (8).

The thickness of the nitride layer is controlled by the relative rates of nitride formation and decomposition, and the temperatures prevailing during synthesis conditions would favor relatively thick surface nitride layers. It is also pertinent to recall the well-known work on the effect of promoters, showing that nonreducible oxides tend to concentrate on the surface of the crystallites (9).

If this picture of the surface is accepted, the equilibrium of formation of the surface compound by means of reaction step (a) should be described in terms of the chemical composition of the layer compound including point defects and stoichiometric deviations. Assuming the presence on the surface of exposed $\mathrm{Fe}$ atoms, SC, as point defects (similar to excess or interstitial cations) capable of a single ionization, the corresponding equilibria are 
$2 \mathrm{NH}_{3}+2 \mathrm{SC}^{+}+2 \mathrm{e}^{-}=2 \mathrm{H}_{2}$ + surface compound

for model (I), and

$$
\begin{aligned}
2 \mathrm{NH}_{3}+\mathrm{SC}^{+}+ & \mathrm{e}^{-}=2 \mathrm{H}_{2} \\
+ & \text { surface compound }
\end{aligned}
$$

for model (II). Reaction equilibria with neutral or doubly ionized defects may also be written, but in the absence of experimental evidence in favor of any one type of defect species, consideration of possibilities other than reactions (13) and (14) will not add significantly to the discussion. Assuming the validity of the direct application of the mass action expression to equilibria (13) and (14) and of conditions of electrical neutrality at the surface, one gets

$$
\begin{aligned}
& {\left[\mathrm{SC}^{+}\right]_{13}=\left[\mathrm{e}^{-}\right]_{13} \propto\left(p_{\mathrm{NH}_{8}} / p_{\mathrm{H}_{2}}\right)^{-1 / 2}} \\
& {\left[\mathrm{SC}^{+}\right]_{14}=\left[\mathrm{e}^{-}\right]_{14} \propto\left(p_{\mathrm{NH}_{8}} / p_{\mathrm{H}_{2}}\right)^{-1}}
\end{aligned}
$$

We may consider that for reaction step (a) the kinetically significant surface centers in model (I) are $\mathrm{SC}^{+}$ions, or by means of expression (15)

$$
\mathrm{N}_{2}(\mathrm{~g})+\mathrm{H}_{2}(\mathrm{~g})+2 \mathrm{SC}^{+} \rightarrow\left(\mathrm{N}_{2} \mathrm{H}_{2} \cdot 2 \mathrm{SC}\right)^{2+}(\mathrm{a})
$$

with a rate coefficient,

$$
k_{\text {expt1 }}=k\left[\mathrm{SC}^{+}\right]^{2}=k^{\prime}\left(p_{\mathrm{NH}_{3}} / p_{\mathrm{H}_{2}}\right)^{-1}
$$

This is consistent with the rate coefficient required by Eq. (11a). Since it is possible that the surface compound still retains a high population of free electrons, small variations in their concentration can be neglected in the rate expression.

Conversely, it may occur that the surface compound is depleted of free electrons, which become kinetically significant for the reactivity of the surface, namely,

$$
\mathrm{N}_{2}(\mathrm{~g})+\mathrm{H}_{2}(\mathrm{~g})+2 \mathrm{e}^{-} \rightarrow\left(\mathrm{N}_{2} \mathrm{H}_{2}\right)^{2-}(\mathrm{a})
$$

The rate coefficient is again consistent with the required one. Finally, the model (II) and the rate-controlling step (a)

$$
\mathrm{N}_{2}(\mathrm{~g})+\mathrm{H}_{2}(\mathrm{~g})+\mathrm{SC}^{+} \rightarrow\left(\mathrm{N}_{2} \mathrm{H}_{2} \mathrm{SC}\right)^{+}(\mathrm{a})
$$

or

$$
\mathrm{N}_{2}(\mathrm{~g})+\mathrm{H}_{2}(\mathrm{~g})+\mathrm{e}^{-} \rightarrow\left(\mathrm{N}_{2} \mathrm{H}_{2}\right)^{-}(\mathrm{a})
$$

and introducing Eq. (16) it is found

$$
k_{\text {expt1 }} \propto\left(p_{\mathrm{NH}_{2}} / p_{\mathrm{H}_{2}}\right)^{-1}
$$

Thus surface models (I) and (II) together with reaction equilibria (13) and (14) provide the basis for a satisfactory interpretation of the experimental results.

\section{Carbon Monoxide Conversion}

The activity of several substances to catalyze the water-gas shift reaction,

$$
\mathrm{CO}+\mathrm{H}_{2} \mathrm{O} \rightarrow \mathrm{CO}_{2}+\mathrm{H}_{2}
$$

has been studied by several authors and various mathematical expressions for the reaction rate are available. The interpretation of the former has generally been cast within the framework of the "frozen" surface model with a fixed physicochemical structure, and the variation in behavior among catalysts has been taken into account by postulating a suitable distribution function for the controlling surface property.

On Ru catalysts the following rate expression was found valid for wide ranges of experimental conditions (10):

$$
d p_{\mathrm{CO}_{2}} / d t=k p_{\mathrm{CO}}\left(p_{\mathrm{H}_{2} \mathrm{O}} / p_{\mathrm{H}_{2}}\right)^{1-\alpha}
$$

with $\alpha \cong 0.5$. The interpretation of Eq. (18) was set forth assuming that reaction (17) occurred in two consecutive elementary steps:

$$
\begin{aligned}
\mathrm{H}_{2} \mathrm{O}(\mathrm{g}) & \rightarrow \mathrm{H}_{2}(\mathrm{~g})+\mathrm{O}(\mathrm{a}) \\
\mathrm{CO}(\mathrm{g})+\mathrm{O}(\mathrm{a}) & \rightarrow \mathrm{CO}_{2}(\mathrm{~g})
\end{aligned}
$$

and that the rate of step (d) was slower than that of step (c). By describing the fast reaction step with a suitable reaction isotherm and expressing the overall rate of reaction (17) as the rate of step (d), the experimental expression (18) was easily reproduced $(10)$.

In analogy with the preceding discussion on reaction (1) we shall show that rate expression (18) may also be obtained by considering that equilibration reactions between gas and solid phases take place during the calalytic conversion. The demonstration is similar to that presented in the previous section. We shall summarize the 
important results only. The rates of steps giving

(c) and (d) are

$v_{\mathrm{c}} / A=k_{\mathrm{c}} f_{\mathrm{c}}([\mathrm{O}]) p_{\mathrm{H}_{2} \mathrm{O}}-k_{\mathrm{e}}^{\prime} f_{\mathrm{e}}^{\prime}([\mathrm{O}]) p_{\mathrm{H}_{2}}$

$v_{\mathrm{d}} / A=k_{\mathrm{d}} f_{\mathrm{d}}([\mathrm{O}]) p_{\mathrm{CO}}-k_{\mathrm{d}}^{\prime} f^{\prime}{ }_{\mathrm{d}}([\mathrm{O}]) p_{\mathrm{CO}_{2}}$

where $[\mathrm{O}]$ is the concentration of adsorbed oxygen. The equilibrium condition for reaction step (c) gives

$$
[\mathrm{O}]_{\text {equil }(\mathrm{c})}=K_{\mathrm{e}}\left(p_{\mathrm{H}_{2} \mathrm{O}} / p_{\mathrm{H}_{2}}\right)
$$

where $K_{\mathrm{c}}$ is the equilibrium constant for reaction step (c). Substituting Eq. (21) into the rate expression (19) and using the expression for the rate at equilibrium $v_{\mathrm{c}}=0$, it is found that

$v_{\mathrm{c}} / A=k_{\mathrm{c}} f_{\mathrm{c}}([\mathrm{O}])\left[p_{\mathrm{H}_{2} \mathrm{O}}-\left(1 / K_{\mathrm{c}}\right)[\mathrm{O}]_{\text {equil (c) }} p_{\mathrm{H}_{2}}\right]$

For reaction step (d), introducing the conditions

$$
[\mathrm{O}]_{\text {equil (d) }}=\left(1 / k_{\mathrm{d}}\right)\left(p_{\mathrm{CO}_{2}} / p_{\mathrm{CO}}\right)
$$

where $K_{\mathrm{d}}$ is the equilibrium constant for reaction step (d) and $v_{\mathrm{d}}=0$, it is found that

$v_{\mathrm{d}} / A=k_{\mathrm{d}} f_{\mathrm{d}}([\mathrm{O}])\left[p_{\mathrm{CO}}-\left(p_{\mathrm{CO}_{2}} / K_{\mathrm{d}}[\mathrm{O}]_{\text {equil (d) }}\right)\right]$

The following conditions are set forth: $[\mathrm{O}]_{\mathrm{ss}} \cong[\mathrm{O}]_{\mathrm{equil}(\mathrm{c})}, \quad(\mathrm{ii}) v_{\mathrm{ss}}=v_{\mathrm{d}}, \quad(\mathrm{iii}) f_{\mathrm{d}}([\mathrm{O}])=$ $[\mathrm{O}]^{\mathrm{m}_{\mathrm{d}}}$, (iv) neglect reverse reaction in elementary step (d). Introducing these conditions into Eq. (24)

$$
v_{\mathrm{d}} / A=k_{\mathrm{d}} K_{\mathrm{c}}^{-m_{\mathrm{d}}} p_{\mathrm{CO}}\left(p_{\mathrm{H}_{2} \mathrm{O}} / p_{\mathrm{H}_{2}}\right)^{m_{\mathrm{d}}}
$$

Taking $m_{\mathrm{d}}=0.5$, Eq. (25) is similar to the experimental equation (18). In this instance,

$$
k_{\text {expt1 }}=k_{\mathrm{d}} K_{\mathrm{c}}^{0.5}\left(p_{\mathrm{H}_{2} \mathrm{O}} / p_{\mathrm{H}_{2}}\right)^{0.5}
$$

The interpretation of expression (26) in terms of equilibrium surface defects is simply carried out. Let us consider excess oxygen anions, $\mathrm{O}^{-}(\mathrm{a})$, as the predominant surface defects $\left(\mathrm{RuO}_{2}\right.$ with a rutile structure is probably an oxygen excess compound and the stoichiometric excess may in principle be present as excess anions).

The corresponding equilibrium defect reaction is

$$
\mathrm{H}_{2} \mathrm{O}(\mathrm{g})=\mathrm{H}_{2}(\mathrm{~g})+\mathrm{O}^{-}(\mathrm{a})+\mathrm{e}^{-}
$$

$$
\left[\mathrm{O}^{-}(\mathrm{a})\right] \propto\left(p_{\mathrm{H}_{2} \mathrm{O}} / p_{\mathrm{H}_{2}}\right)^{0.5}
$$

If the rate-controlling step of reaction (17) is written as

$$
\mathrm{CO}(\mathrm{g})+\mathrm{O}^{-}(\mathrm{a}) \rightarrow \mathrm{CO}_{2}+\mathrm{e}^{-}
$$

The rate coefficient $k_{28}=k_{28}^{\prime}\left(p_{\mathrm{H}} / p_{\mathrm{H}_{2}}\right)^{0.5}$ is consistent with that required by the experimental results [Eq. (26)]. We conclude that on the surface of $\mathrm{Ru}$, operating under the conditions of validity of reaction Fq. (18), the stationary surface oxygen concentration is near the oxidation side. A similar situation was found valid for $\mathrm{Re}, \mathrm{Fe}$, and $\mathrm{Rh}$ catalysts, while for $\mathrm{Pd}, \mathrm{Pt}$, and $\mathrm{Ag}$ catalysts a surface oxygen level closer to the reduced side was found to be in better agreement with the experimental results (11). The details of the structure of the equilibrium surface layers of oxygen during the catalytic water-gas shift reaction must be worked out yet. There is already evidence for the formation on the same metal of oxygen layers with strikingly different characteristics (12).

\section{Discussion}

Let us bricfly analyze the principal assumptions upon which the development of the previous sections rests.

The validity of the application of the ideal mass action expression to surface equilibria (13), (14), and (27) is a crucial point for the preceding derivations. Experimental conditions of low surface coverage are necessary. This situation may have been present in most of the previous studies but a confirmation of this should be obtained. Kinetically meaningful measurements of surface coverage are difficult to obtain, and in some instances a clear definition of surface coverage is difficult. Consider, for example, two structures of an oxygen layer on a metal M:

$\mathrm{MOOMOMOO}$

$\mathrm{M} \mathrm{M} O \mathrm{M} \mathrm{O} \mathrm{MO}$

M M M M M M M

(III)

Using conventional measurements of surface

coverage one concludes that the same surface

O

M M M M M M M

M M M M M M M

(IV) 
coverage $(\mathrm{O} / \mathrm{M}$ ratio) is present in both instances while, in fact, in case (III) the number of surface-held oxygens which contribute to the kinetic reactivity of the surface is smaller than in case IV.

Interactions of electrical charges of surface ions have been considered absent in the previous analysis. In principle, the corresponding activity coefficients can be calculated on the basis of the Debye and Hückel theory. Alternatively, one may introduce the concept of ionic strength among surface ions, but meaningful computations are difficult.

Association among surface centers may also modify the position of surface equilibria. The effect on the enthalpy may be due to Coulomb interaction with or without polarization effects, to covalent bonding, and to elastic and vibrational effects. Since the contribution of the enthalpy is generally preponderant over that of the entropy, it seems reasonable to expect association among charged surface centers whenever

$\left|\Delta H_{\text {ass }}\right| \geqslant 2 \vec{k} T$ or for $\Delta H_{\text {ass }}>\sim 2 \mathrm{kcal} / \mathrm{mole}$

Thus, this contribution may generally be neglected, except at sufficiently low temperatures where phase transitions between different layer structures of the adsorbate have been clearly identified (13).

Under some conditions the surface layer may become electrically charged with respect to the bulk of the solid. This situation will alter the equilibrium distribution of electrons between surface and bulk and, as a result, the value of the exponent $m$ in the previous derivations will be modified. This effect can be introduced into the previous analysis in a quantitative fashion. For example, in the following adsorption equilibrium:

$$
\mathrm{CO}_{2}+\mathrm{AV}^{+}+\mathrm{e}^{-}=\mathrm{CO}+\text { solid oxide }
$$

a thin surface charge layer gives

$$
\begin{array}{r}
{\left[\mathrm{O}^{-}\right]_{\mathrm{ads}} \propto\left(p_{\mathrm{CO}_{2} /} / p_{\mathrm{CO}}\right)^{1 / 2} \text { and }\left[\mathrm{O}^{-2}\right]_{\mathrm{ads}}} \\
\propto\left(p_{\mathrm{CO}} / p_{\mathrm{CO}}\right)^{0}
\end{array}
$$

for the two possibilities of adsorption $\mathrm{O}^{-}$and $\mathrm{O}^{2-}$, while a thick layer gives (14)

$$
\begin{array}{r}
{\left[\mathrm{O}^{-}\right]_{\mathrm{ads}} \propto\left(p_{\mathrm{CO}_{2}} / p_{\mathrm{CO}}\right)^{0} \text { and }\left[\mathrm{O}^{-2}\right]_{\mathrm{ads}}} \\
\propto\left(p_{\mathrm{CO}_{3}} / p_{\mathrm{CO}}\right)^{-1 / 5}
\end{array}
$$

It is clear that the calculation of the Debye length at the surface is generally necessary to indicate the possibility that electrical effect may modify the value of $m$.

In the previous analysis, the important defect equilibrium expression is supplemented with the correct expression for the rate-controlling step. As a limiting case the latter may include only electronic defects (15). In this formulation, the rate of reaction was written

$$
v=A p n
$$

where $n, p$ are the free electron concentration and gas pressure, respectively, and

$$
A=\frac{\nu \mu \sigma}{2(M \bar{k} T)^{1 / 2}}\left(\frac{2 \pi \bar{k} T}{m^{*}}\right)^{1 / 2} \exp \left\{\frac{Q-E}{k T}\right\}
$$

where $\nu, \mu$ are probability coefficients; $M, m^{*}$, molecular and electron mass; and $\sigma$, collision diameter. In expression (29) $n$ is assumed to bc indepcndent of the partial pressurc of the gas phase. This may be valid only for very large $n$. In addition, by writing the rate of reaction as proportional to the first power of the partial pressure of the reagent gas, no provision was made for specific surface effects. This formulation is more appropriate for the models of "frozen" surface and, thus, adequate to analyze the influence of solid admixtures (doping) rather than to describe the modification of the surface activity as a result of gas-phase interactions.

Problems related to surface topology may in principle be included in the previous analysis and the various adsorption possibilities related to the presence of surface step, grain boundaries, dislocation termini, and surface roughness may be considered in the appropriate manner (16).

Alternatively, if surface mobility and equilibration are slow, these surface features may be formally introduced in the kinetic expressions by statistical treatments. Thus, equilibrium surface models should be viewed as complements to conceptual schemes which emphasize a fixed surface structure (17).

\section{Conclusion}

Since no single interpretation of all catalytic effects is likely to be correct, the present 
discussion should be viewed as a complement to previous analysis of the $\mathrm{NH}_{3}$ synthesis and $\mathrm{CO}$ conversion reactions. At low temperatures, the "frozen" surface approach gives an adequate representation of solid-gas interactions, while the equilibrium model, as here discussed, becomes morc appropriate and justifiable physically at higher temperatures.

The present analysis is based upon several assumptions for which there is little direct justification at present, but it represents a departure from the schemes of surfaces previously suggested for the interpretation of the experimental results on $\mathrm{NH}_{3}$ synthesis and $\mathrm{CO}$ conversion. The crucial assumption is that of a surface layer formed during catalysis by reaction between catalyst and gas phase. Surface reactivity and catalytic activity are then dependent upon equilibration reactions between the surface layer and the surrounding gas phase.

\section{ACKNOWLedGMent}

Support of this work by a grant from the National Science Foundation is gratefully acknowledged.

\section{ReFerences}

1. Boreskov, G. K., Zh. Fiz. Khim. 33, 1969 (1959).

2. Langmuir, I., and Taylor, J. B., Phys. Rev. 40, 463 (1932); Nickerson, R. A., ANn PARKer, E. R., Trans. Am. Soc. Metals 42, 376 (1950); Geguzin, Y. E., and Kovalev, G. N., Dokl. Akad. Nauk SSSR 149, 1290 (1963).
3. WaGner, C., AND HaUfre, K., Z. Elektrochem. 44, 172 (1938); Wagner, C., J. Chem. Phys. 18, 69 (1950); Kobayashi, H., AND Wagner, C., ibid. 26, 1609 (1957).

4. STu't, S., Ber. Bunsengesellschaft 70, 37 (1966).

5. Temkin, M., And Pyzhev, V., Acta Phys.Chem. USSR 12, 327 (1940); Zh. Fiz. Khim. 13, 85I (1939); Brill, R., J. Chem. Phys. 19, 1047 (1951).

6. Ozaki, A., Taylor, H. S., and Boudart, M., Proc. Royal Soc. London 258A, 47 (1960).

7. Garneitt, J. L., and Sollich-Baumgartner, W. A., Advan. Catalysis 16, 95.

8. Tamaru, K., Trans. Faraday Soc. 56, 1410 (1960); Proc. Intern. Congr. Catalysis, 3rd, Amsterdam, 1965, p. 664 (1966).

9. Brunauer, S., and Emmett, P. H., J. Am. Chem. Soc. 59, 310, 1553 (1937); 62, 1732 (1940).

10. Parravano, G., Ind. Eng. Chem. 49, 266 (1957).

11. Parravano, G., in "Chimica e Dinamica della Catalisi," p. 65. Consiglio Nazionale delle Ricerche, Roma, 1964.

12. Roberts, M. W., and Wells, B. R., Paper presented at the discussion of the Faraday Society, Liverpool, April, 1966.

19. Erhlich, G., Proc. Intern. Congr. Catalysis, Brd, Amsterdam, 1965, p. 113 (1966).

14. Cha, D. Y., and Parravano, G., unpublished results.

15. Vol'Kenstein, F. F., Zh. Fiz. Khim. 22, 311 (1948).

16. Dunnina, W. J., J. Phys. Chem. 67, 2033 (1963).

17. Parravano, G., Ind. Eng. Chem. 58, 45 (1966). 